\title{
Questões de multimodalidade e produção de sentidos em charges sobre o programa Mais Médicos
}

Multimodality and sense making issues in some multimodal texts about brazilian public health program Mais Médicos (More Doctors)

Ana Elisa Ribeiro

Centro Federal de Educação Tecnológica de Minas Gerais

Resumo: Neste trabalho, busca-se analisar processos discursivos ligados à produção e à leitura de textos multimodais (charges) gerados por um evento político e midiático amplamente conhecido como Mais Médicos. Em um momento histórico em que o governo brasileiro contratou médicos estrangeiros para o atendimento de parcelas desassistidas da população, especialmente em localidades precárias e de difícil acesso, muitos textos foram produzidos e publicados, em todas as mídias, explicitando posicionamentos pró e contra essa ação. Sob forte polêmica, o Mais Médicos foi mantido. Os argumentos e contraargumentos ao programa foram muitos. Com base, principalmente, em Kress (2003), discute-se aqui a questão da circulação de textos multimodais na contemporaneidade, assim como os processos de produção de sentidos a partir de dezoito charges publicadas e amplamente compartilhadas em redes sociais, naquele momento.

Palavras-Chave: Multimodalidade. Multiletramentos. Leitura de imagens.

Abstract: This paper discusses discoursive processes in writing and reading multimodal texts generated by a politician and midiatic brazilian event called Mais Médicos (More Doctors). In a historical moment in which the Brazilian government hires foreign doctors to care for underserved segments of the population, especially in poor localities of difficult access, many texts were produced and published in all media, explaining positions pro and against this action. Under strong controversy, the Best Doctors was maintained. The arguments and counter-arguments to the program were many. Based mainly in Kress (2003), this paper discusses the issue of movement of multimodal texts in contemporary as well as the senses of production processes from eighteen published cartoons widely shared on social networks at that time.

Keywords: Multimodality. Multiliteracy. Reading images. 


\title{
1. Considerações iniciais sobre multiletramentos
}

É de Roxane Rojo a seguinte formulação:

\begin{abstract}
(...) o conceito de multiletramentos - é bom enfatizar - aponta para dois tipos específicos e importantes de multiplicidade presentes em nossas sociedades, principalmente urbanas, na contemporaneidade: a multiplicidade cultural das populações e a multiplicidade semiótica de constituição dos textos por meio dos quais ela se informa e se comunica (ROJO, 2012, p. 13, grifo no original).
\end{abstract}

Ana Elisa Ribeiro

Com isso, é a noção de multiletramentos, assim formulada, que nos guia nas considerações que este artigo pretende fazer, ainda que assumamos uma assimetria: trataremos muito mais da segunda parte dessa definição, isto é, aquela segundo a qual os multiletramentos dizem respeito à "multiplicidade semiótica" com a qual lidamos nos dias de hoje. E além: entendemos que essa multiplicidade esteja ligada não apenas à circulação e à emergência de gêneros discursivos ${ }^{1}$ variados, textos diversos, mas também à maneira como eles ocorrem, surgem, são editados, passam a circular e são lidos. Esse é um cenário francamente alterado, nas últimas décadas, e são fundadas e inspiradas em Gunther Kress (2003) as nossas considerações sobre os textos e suas formas de circulação.

Para Kress (2003, p. 1), "não é mais possível pensar sobre o letramento isoladamente de uma vasta gama de fatores sociais, tecnológicos e econômicos"2. Muito embora esse autor faça parte do Grupo de Novas Londres (New London Group), que propôs uma nova pedagogia para o futuro $^{3}$, inclusive cunhando o termo multiliteracies (assim mesmo, com prefixo e no plural), ele vem manifestando seu descontentamento com a quantidade de derivações sofridas pelo termo "letramento", incluindo suas adjetivações, conforme se nota em algumas de suas afirmações. Para ele, "[L] letramento é o termo para se usar quando produzimos mensagens usando letras" (p. 23), assim como "Numeramento para o uso de números" (p. 2). No entanto, o autor afirma:

\footnotetext{
1 Não vamos aqui discutir o conceito de gênero. Apenas com a finalidade de encontrar coerência com Kress (2003), este é o modo como ele trata dos gêneros na obra em foco: "Trato o gênero como a categoria que materializa as relações sociais dos participantes envolvidos no texto como interação" (p. 108). 2 Todos os trechos traduzidos são de nossa responsabilidade, já que a obra não foi editada em português. 3 Ver o artigo completo conforme referências: Cazden et al. (1996). o termo multiletramentos tem sido amplamente adotado no Brasil. A proposta do grupo é de meados dos anos 1990.
} 
Minha abordagem nos livra do problema de encontrar novos termos para o uso de diferentes recursos: não precisamos de "letramento visual" para o uso de imagem; nem "letramento gestual" para o uso de gestos; e também não "letramento musical" ou "letramento sonoro" para o uso de sons que não sejam a fala; e assim por diante.

\section{E continua Kress (2003), defendendo uma proposta diferente:}

Tenho minhas dúvidas a respeito dessas expressões metafóricas que usamos popularmente em contextos diários e que se estendem infinitamente - letramento visual, letramento gestual, letramento musical, letramento midiático, computacional, cultural, emocional, sexual, internético e assim por diante. Eu gostaria de excluir qualquer outro uso do termo que esteja atualmente na moda, como indicam certos tipos de habilidades de produção menos ou mais associadas a aspectos da comunicação, como no letramento digital ou (aspectos do) letramento midiático. Quero fazer uma distinção triádica na nossa nomeação das práticas: 1 palavras que nomeiam os recursos para representação e seu potencial - fala, escrita, imagem, gesto.

2 palavras que nomeiam o uso dos recursos na produção de mensagens - letramento, oralidade, signing, numeramento, (aspectos do) "letramento digital" e do "letramento midiático", "letramento internético", etc.

3 palavras que nomeiam o envolvimento de recursos para a disseminação dos sentidos como mensagens - internet publishing, por exemplo. (KRESS, 2003, p. 23)

Embora haja outras questões em que não nos estenderemos aqui, é de se destacar que o autor chame de "moda"4 os letramentos adjetivados com os quais temos - inclusive no Brasil - tratado uma série de questões que emergem de usos e circulações linguageiras mais recentes, especialmente para dizer de especificidades que gostaríamos de focalizar. A crítica do autor, no entanto, parece-nos útil para evitar a excessiva diluição de um conceito que quer, de fato, tratar dos textos, da leitura, da escrita, reconhecendo sempre sua história, suas dinâmicas e suas mutações: letramento.

Questões de
multimodalidade
eprodução de
sentidosem
charges sobreo
programa Mais
Médicos

4 No original "currently fashionable use of term...". 
Assumimos, com Rojo (2012), a multiplicidade semiótica dos tempos que correm e queremos, com Kress (2003), admitir a emergência absoluta das telas como espaços de circulação e leitura de textos, inclusive, em certos casos, de maneira prevalente. Além disso, juntamo-nos a este autor na assunção de que a circulação dos textos, tal como ocorre contemporaneamente, traz demandas de leitura também específicas deste tempo ${ }^{5}$. Uma dessas demandas, segundo ele, pode ser assim expressa:

Não podemos mais esperar compreender os textos escritos olhando apenas os recursos da escrita sozinha. Eles precisam ser vistos no contexto da escolha de modos que foi feita, os modos que aparecem junto com a escrita, e também no contexto dos modos que não foram escolhidos. (KRESS, 2003, p. 11)

Kress (2003) afirma que uma teoria de letramento pode não ser completa, mas pode oferecer boas ferramentas, no entanto, é enfático em afirmar que uma teoria exclusivamente linguística não dá conta desse objeto complexo que é o texto multimodal. É importante trazer a citação do autor:

Os $\operatorname{modos}^{6}$ que ocorrem juntamente com os modos linguísticos de fala e escrita, em páginas e telas, são constituídos por princípios diferentes daqueles da língua; sua materialidade é diferente; e o trabalho das culturas com elas é também diferente. A mudança teórica vai da linguística para a semiótica - de uma teoria que considera a língua sozinha para uma outra que considera, igualmente, o gesto, a fala, a imagem, a escrita, objetos 3D, cor, música e sem dúvida outros. Nessa teoria, os modos linguísticos - fala e escrita - também terão de se relacionar semioticamente; eles são agora parte de uma paisagem maior de muitos modos disponíveis para representação - embora, é claro, eles tenham um status muito valorizado na sociedade e, no caso da fala, certamente ainda carregue a maior parte da comunicação (KRESS, 2003, p. 36).

50 historiador Roger Chartier vem afirmando as diferenças entre textos impressos e textos digitais, sendo uma delas a perda do dimensionamento do objeto quando da sua leitura. Uma tela traz textos redobrados, escamoteados, que não revelam, por vezes, nem mesmo onde estão publicados. Ver, por exemplo, Chartier $(1998 ; 1998 \mathrm{a} ; 2001 ; 2002)$.

6 Grosso modo, a definição de modo em Kress (2003, p. 45) é: "Modo é o nome dado a um recurso cultural e socialmente cunhado para a representação e a comunicação. 0 modo tem aspectos materiais." 
Nesse sentido, o estudo dos textos em suas relações semióticas porque é impossível que um texto seja feito apenas de letras ou língua que não se relaciona com mais nada - em muito nos interessa, especialmente porque são francamente predominantes, nos vários espaços de comunicação com que vimos lidando socialmente, incluindo-se aí telas de todos os tamanhos e mídias mais tradicionais.

A relação texto/imagem, que por vezes é tratada como uma interação apenas ilustrativa, com a imagem na função complementar, passa a ser focalizada também nos estudos linguísticos, como parte fundante de uma peça chamada texto, justamente porque se trata de uma tessitura, de uma rede de signos ou modos que trabalham em composição.

Passaremos, então, à aproximação com uma situação geradora de muitos textos, impressos e digitais, circulantes de várias maneiras, amplamente lidos e debatidos pelas pessoas, mesmo que de maneira precariamente informada: charges sobre o programa governamental brasileiro conhecido como Mais Médicos.

\section{Texto: palavra, imagem, modos}

“A produção de texto é um complexo processo de orquestração" (KRESS, 2003, p. 135). E tal orquestração não passa apenas por uma escolha de palavras ou mesmo pela ilustração do texto, mas por uma série de mobilizações ligadas a outros textos, de variadas composições, além de discursos que circulam de diversas formas na sociedade. A combinação de elementos tais como escrita e imagem forma, em muitíssimos casos, uma "entidade textual coerente", como denomina Kress (2003), do que decorre que "escrita e imagem precisam ser lidos juntos, numa entidade textual". A profusão desses textos multimodais - focalizando aqui apenas texto/imagem - em nossa "paisagem comunicacional" nos devolve à questão levantada por Kress (2003, p. 142): “Por que deveria nos preocupar - para aqueles que estão preocupados - a inclusão da imagem no escopo da leitura?" Está entre as razões uma necessidade premente de compreensão de textos em que vários modos estão orquestrados, de maneira intricada. Parafraseando Kress (2003), é especialmente relevante, nos dias de hoje, compreender que gênero e discurso sejam elementos inescapáveis do estudo do texto, já que a palavra, isoladamente, fornecerá uma teoria ou uma explicação apenas parcial do processo de produção de sentido. Segundo o autor, é absolutamente necessário hoje considerar aspectos como a tela, a aparência ou os modos de circulação de um texto, a fim de compreendê-lo. 
A diversidade semiótica mencionada por Rojo (2012) encontra aqui uma afirmação de Kress (2003, p. 39), para quem “[T]tanto na escrita quanto na leitura o sentido é resultado do trabalho semiótico". No entanto, a aprendizagem desse trabalho não é simples, às vezes precisa ser mediada, ensinada, estimulada. Os elementos que estão em jogo em um texto multimodal podem não dizer respeito apenas ao que se aprende sobre coesão e coerência em textos, ou sobre aspectos da textualidade, como a linguística a tinha entendido, até há pouco. Para além do texto como unidade formal, podemos nos aplicar na tarefa de analisar ou levantar questões sobre textos cujas composições - orquestrações - dependem da tessitura de diversos modos ou linguagens, como teorias semióticas já percebiam. E é o que faremos a seguir, após alguns esclarecimentos.

\section{Um programa polêmico de governo}

A polêmica é terra fértil para a produção textual. Se pensarmos nas redes sociais $^{7}$ - tais como Twitter ou Facebook - como espaços de discussão, uma espécie de ágora para o debate, veremos que tudo ali funciona por meio de textos multimodais, compartilhados com as mais diversas fontes, incluindo jornais, revistas, sites e blogs. Seguem-se aos compartilhamentos os comentários, as ressignificações dos próprios posts, as "curtidas" e o debate em torno de temas que estejam latentes em nossa sociedade.

O Programa Mais Médicos (PMM) foi um desses temas polêmicos, que dividiu a sociedade em grupos pró e contra a vinda de médicos estrangeiros para trabalhar no sistema público de saúde do Brasil. Segundo a página oficial do PMM, o Programa

\footnotetext{
é parte de um amplo esforço do Governo Federal, com apoio de estados e municípios, para a melhoria do atendimento aos usuários do Sistema Único de Saúde (SUS). Além de levar mais médicos para regiões onde há escassez ou ausência desses profissionais, o programa prevê, ainda, mais investimentos para construção, reforma e ampliação de Unidades Básicas de Saúde (UBS), além de novas vagas de graduação, e residência médica para qualificar a formação desses profissionais. (PMM, 2015)
}

7 Para um estudo mais aprofundado sobre redes sociais, com fundamentação sociológica, ver Recuero (2009; 2012). 
Os números oficiais divulgados dão conta de que o PMM oferece 18.240 vagas para médicos em 4.058 municípios brasileiros, o que cobre $73 \%$ das cidades e dos distritos sanitários especiais indígenas (PMM, 2015). Uma linha do tempo no site oficial informa uma série de ações e benefícios ocorridos ao longo de seu pouco tempo de existência - o Mais Médicos foi lançado em 2013.

A despeito da propaganda positiva nas fontes oficiais, uma intensa discussão em torno do PMM ganhou as ruas, em 2013, e se estendeu. Os discursos sobre a medicina, os médicos, a saúde pública brasileira e outros aspectos se espraiaram de tal forma que qualquer pessoa seria capaz de uma opinião sobre o caso. Muitos estavam a favor da vinda dos estrangeiros para ocupar espaços em que os médicos brasileiros não atuavam, outros tantos contra a vinda de estrangeiros, especialmente cubanos, para ocupar vagas que seriam para profissionais do Brasil.

No entanto, juntamente com esses aspectos mais amplos da discussão, que pareciam polarizar argumentos e posicionamentos, outros discursos compareciam, fazendo com que emergissem textos que ajudavam tanto a esclarecer o programa quanto a expor opinião contrária. o leitor desavisado poderia, facilmente, cair nas armadilhas de crônicas, comentários, notícias, reportagens, charges, tirinhas, todos dispostos a apresentarem seu ponto de vista sobre o PMM. É o caso das charges, que nos ocupam aqui, empregando recursos modais diversos, ao conformar um texto engendrado por modulações e linguagens de mais de uma natureza.

Observando a profusão de textos sobre o tema PMM circulantes nas redes sociais, a partir de 2013, passamos a nos ocupar das peças que consideramos interessantes para uma visada sobre a composição e a produção de sentidos nesses materiais, como mostraremos na seção a seguir.

\section{Mais Médicos: uma polêmica geradora de textos}

Apresentamos aqui 18 charges publicadas em jornais, blogs ou revistas eletrônicas, ao longo dos últimos dois anos, mas especialmente no ano de 2013, quando a polêmica sobre o Programa Mais Médicos foi mais forte no país. Para além de considerações - ainda que insuficientes sobre a materialidade desses textos, em relação a seus modos de publicação e circulação, buscaremos também mencionar sua composição multimodal, a maneira como os recursos modais são "orquestrados" em cada um, além da mobilização de outros discursos ou outros textos que 


\section{Ana Elisa Ribeiro}

podem funcionar como inspiração, ou como motor da intertextualidade em cada um. Passemos, então, aos comentários, distribuindo as peças em blocos por posicionamento a respeito do PMM.

\subsection{Construindo um posicionamento a favor do PMM}

As charges desta seção são aquelas que consideramos favoráveis ao Programa Mais Médicos, isto é, de algum modo, ainda que sob argumentos diferentes, o texto, composto por palavra e imagem, constrói uma posição a favor do PMM. Para isso, mobiliza, especialmente, conhecimentos de mundo do leitor brasileiro, presumindo um cidadão que sabe das mazelas do país no setor da saúde e que, em tese, seria beneficiado por um programa como este.

A Fig. 1 apresenta uma charge que mostra uma cena conhecida do cidadão: uma espécie de recepção de consultório ou posto médico. A atendente, provavelmente uma enfermeira ou técnica, menciona os médicos estrangeiros, ao passo que o paciente, muito machucado, responde que sua "dor não tem fronteiras", fazendo também alusão a outro programa do governo para o intercâmbio de estudantes brasileiros que vão para diversos países. Para que o efeito de humor se consume, é importante que, além de compreender a situação mostrada no quadro, com o script conhecido sobre uma consulta médica, o leitor também faça a associação entre a resposta do paciente e o outro programa de governo que se consolidou nos últimos anos, tornando-se amplamente conhecido. Depreende-se da situação exposta na charge que ao cidadão interessa mais ter o atendimento do que saber se o médico é brasileiro ou não, construindo-se um posicionamento a favor do PMM.

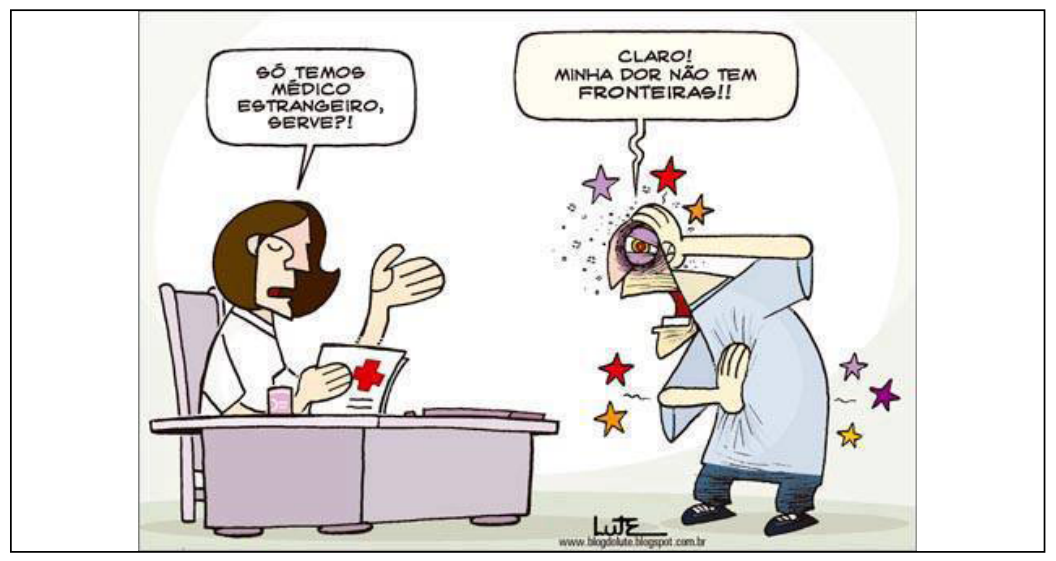

Figura 1. Charge de Lute originalmente publicada no jornal Hoje em dia de 25 de ago. de 2013. FONTE: http://kikacastro.com.br/2013/07/21/mais-medicos-para-o-brasil-criticas-e-consideracoes/ 
De maneira semelhante e mobilizando argumento parecido, a Fig. 2 apresenta também uma situação de recepção de paciente em posto médico, com a pergunta da funcionária sobre médicos de diversas nacionalidades. $O$ paciente que necessita de atendimento também responde no sentido de que qualquer profissional lhe serviria, naquela circunstância, “até” pajé.

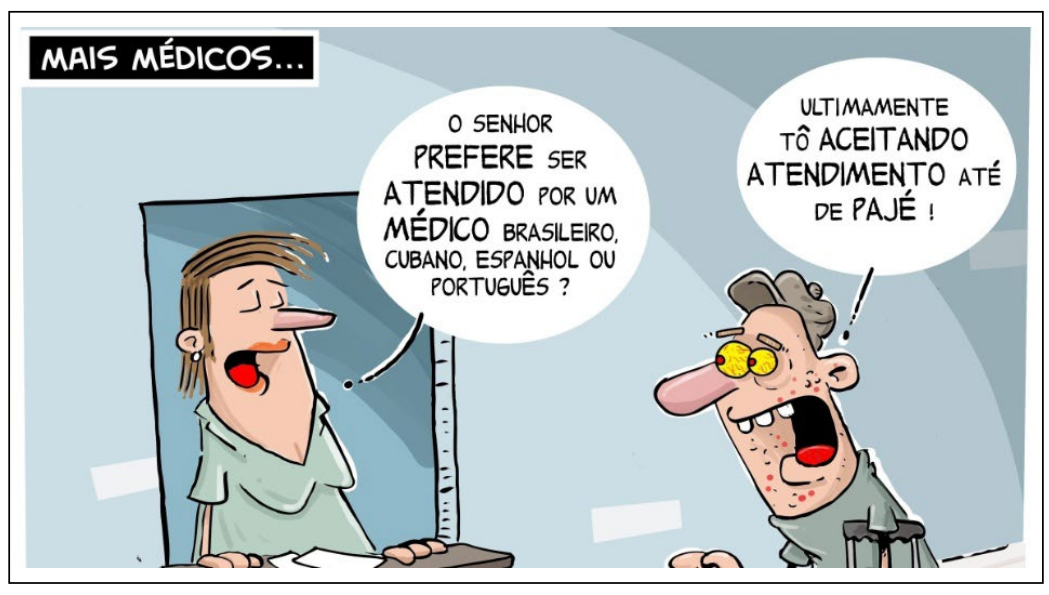

Questões de multimodalidade eprodução de sentidosem charges sobre o programaMais Médicos

Figura 2. Charge sem assinatura, no Nexnotícias

FONTE: http://nexnoticias.webnode.com/news/programa-medicos-no-interior/

Para a consumação do efeito de humor, mais uma vez, caberia ao leitor não apenas compreender a situação macro e o debate público sobre o Programa Mais Médicos, gerador desta charge, mas também a situação da saúde pública no país, com a falta de profissionais para o atendimento da população. O pajé, elemento fundamental na construção dos sentidos desta charge, é uma espécie de "curandeiro" indígena, que o texto rebaixa e qualifica como menor, mas que também serviria na situação de penúria em que se encontra a saúde pública brasileira. 0 estado dos pacientes, em ambas as charges, é mostrado - e não narrado ou descrito -, o que auxilia na orquestração dos sentidos do texto.

A seguir, a Fig. 3 apresenta outra orquestração de modos e sentidos, mobilizando um tipo de referência muito diferente dos textos anteriores, inclusive trazendo uma leitura mais contundente e uma crítica muito mais dura àqueles que seriam contra um programa como o Mais Médicos. A comparação, expressa na forma como o quadro é desenhado, na imagem dos personagens, em seu gesto e em suas palavras, é entre o líder nazista Adolf Hitler, figura amplamente conhecida da história 
mundial, e os médicos contrários ao PMM. Para compreender a dureza do pareamento feito pelo chargista, é necessário mobilizar conhecimentos de história. A identificação com Hitler é condenável em qualquer sentido, o que constrange o leitor que por acaso seja contrário ao PMM.

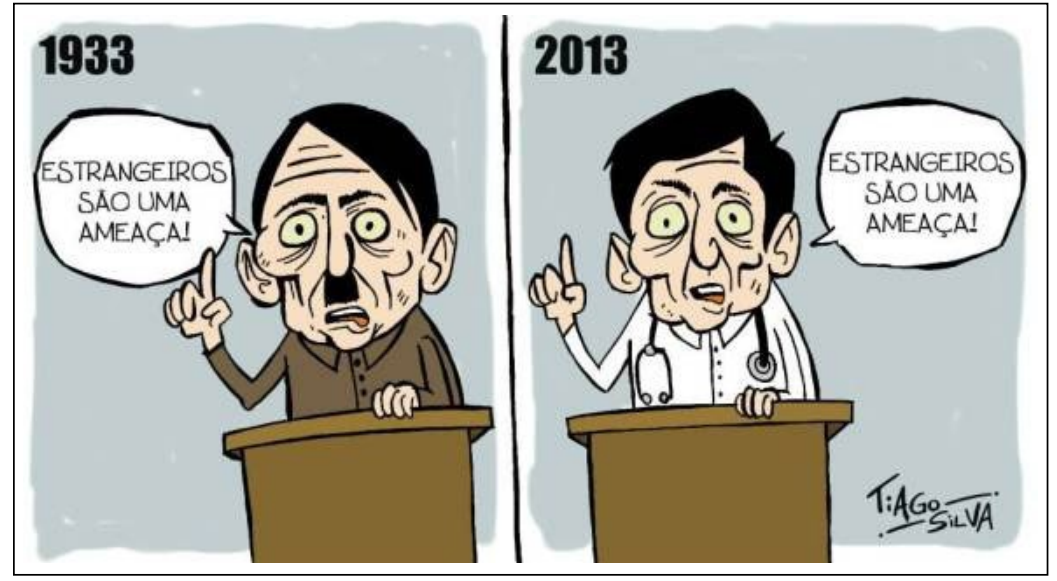

Figura 3. Charge de Tiago Silva

FONTE: http://www.esmaelmorais.com.br/2013/08/charge-do-dia-preconceito-a-medicos-cubanos/

A Fig. 4 mobiliza ainda outro argumento a favor do Mais Médicos. Trata-se da assimetria entre as regiões do Brasil, em que o Nordeste é apresentado como precário e mal atendido. Na charge, médicos estrangeiros (conforme título) são guiados até uma região sem luz. A ideia que sobrevém é a de que uma região mal assistida seria favorecida pela presença desses profissionais.

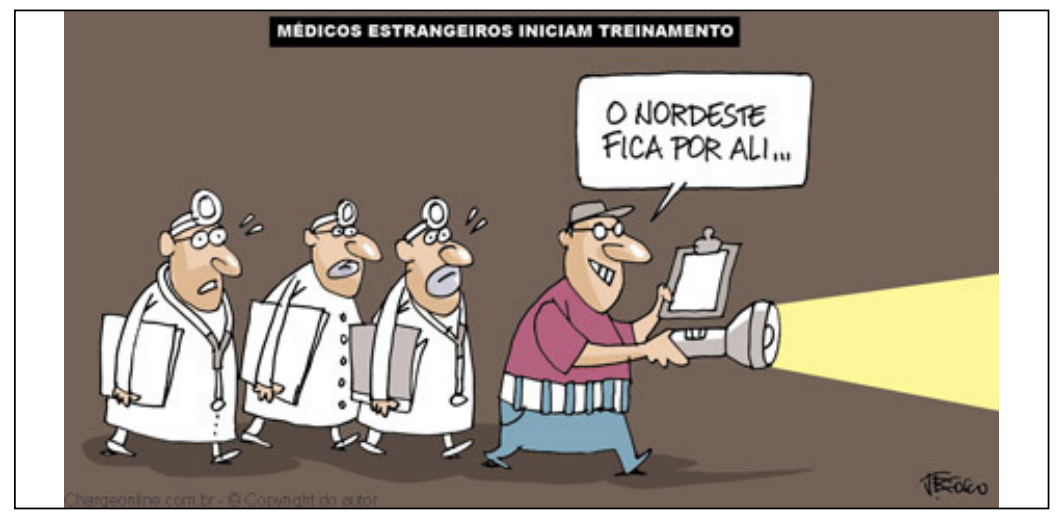

Figura 4. Charge de J. Bosco

FONTE: http://www.luizberto.com/2013/09/02 
Já a Fig. 5 trabalha a imagem do médico elitista, que não quer sujar as mãos em regiões distantes e precárias de um país de dimensões continentais. Ao tecer uma crítica aos médicos - "cínicos" - e construir um posicionamento favorável ao PMM, a charge mobiliza, ao mesmo tempo, a comparação, especialmente na forma como os modos são aí orquestrados (cores, médico se formando e médico formado, layout dividido ${ }^{8}$, etc.). Isso leva o leitor a construir um sentido de que médicos que aceitam as condições ruins de alguns lugares vão beneficiar a população, já que muitos profissionais brasileiros não querem fazer isso, "nem por um bom salário".

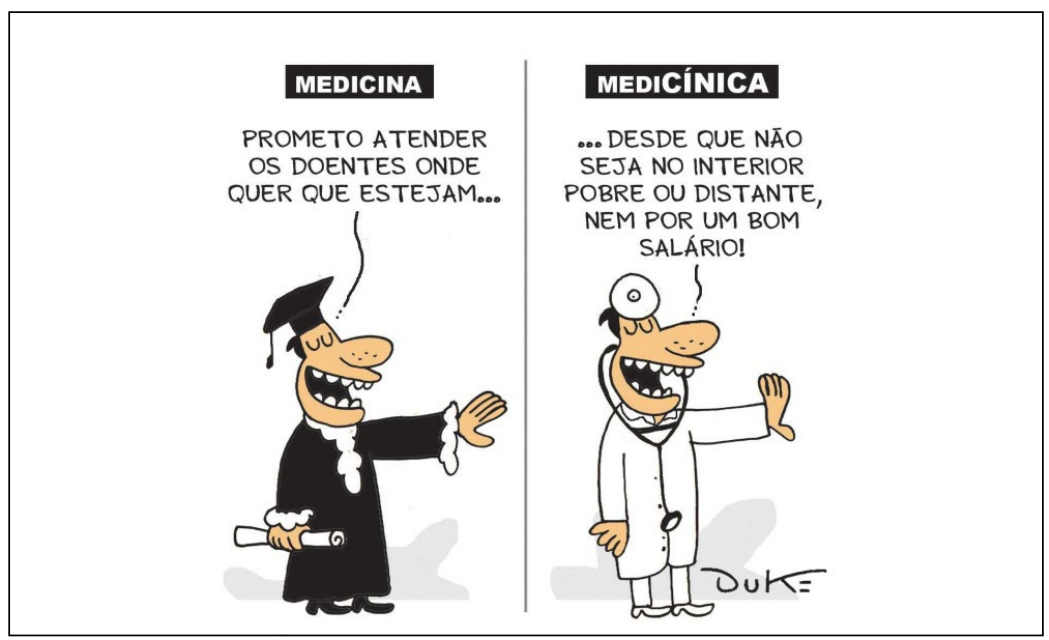

Questões de
multimodalidade
eproduçãode
sentidosem
charges sobreo
programa Mais
Médicos

Figura 5. Charge de Duke

FONTE: http://oquetodomundoquerfalar.blogspot.com.br/2013_08_01_archive.html

De maneira parecida, a charge da Fig. 6 opera com a imagem do médico bem-sucedido que se sente ameaçado pelos colegas estrangeiros. Oferece-se ao leitor a imagem do médico rico, privilegiado, contrário ao PMM. A charge mobiliza um estereótipo de médico muito antipatizado pela população. O texto orquestra imagem e palavra na forma de "etiquetas" que ajudam o leitor a perceber um cenário: a mesa de trabalho do profissional cheia de itens, aos quais a massa da população não tem acesso, como chave de carro

8 Interessante ver em Kress e Van Leeuwen (2006) propostas e considerações sobre o layout, embora tímidas. Em 2003, Kress avança um pouco mais no tratamento do layout como modo. Já sobre uma categoria que os autores chamam de framing (enquadramento), é possível compreender melhor a função de fios, linhas, cores e outros elementos para a coesão ou a separação entre imagens e palavras, imagens e imagens, etc. 
importado, dólares, moradia cara, etc. É interessante mencionar certa semelhança entre a estereotipagem do médico das Figuras 5 e 6, realçando que ambas levam à construção de um posicionamento pró-Mais Médicos.

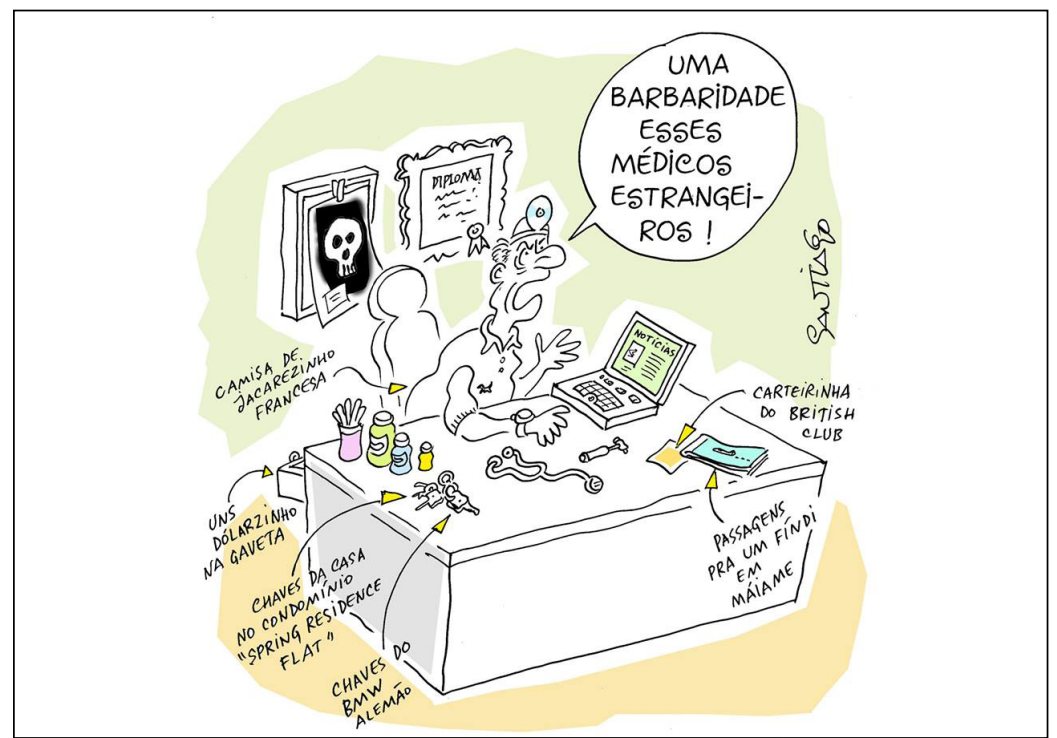

Figura 6. Charge de Santiago

FONTE: http://www.aldeiagaulesa.net/2013/08/cartum-o-corporativismo-medico-contra.html\#.Vs_CSPkrKM8

\subsection{Construindo um posicionamento contrário ao PMM}

Passemos agora às charges contrárias ao Programa Mais Médicos, observando a mobilização de modos - palavra e imagem - para a construção de um texto com argumentos que levem a considerar o PMM ruim para o país.

$\mathrm{Na}$ Fig. 7, é fundamental conhecer o episódio historicamente famoso como Cavalo de Tróia, quando gregos conseguiram introduzir um cavalo de madeira cheio de soldados dentro da cidade inimiga de Tróia. Com isso, venceram a guerra. A expressão é empregada com sentido negativo. Cavalo de Tróia é também o nome dado a malwares, programas nocivos de computador que são introduzidos como vírus, corrompendo a máquina. Do mesmo modo, os médicos estrangeiros são comparados a guerreiros indesejados que saem de um cavalo e derrotam o país. A comparação faz lembrar a da Fig. 3, levando, no entanto, a um posicionamento contrário ao PMM. Os médicos estrangeiros, aqui, são uma ameaça. Na Fig. 3, os médicos brasileiros são os vilões. 


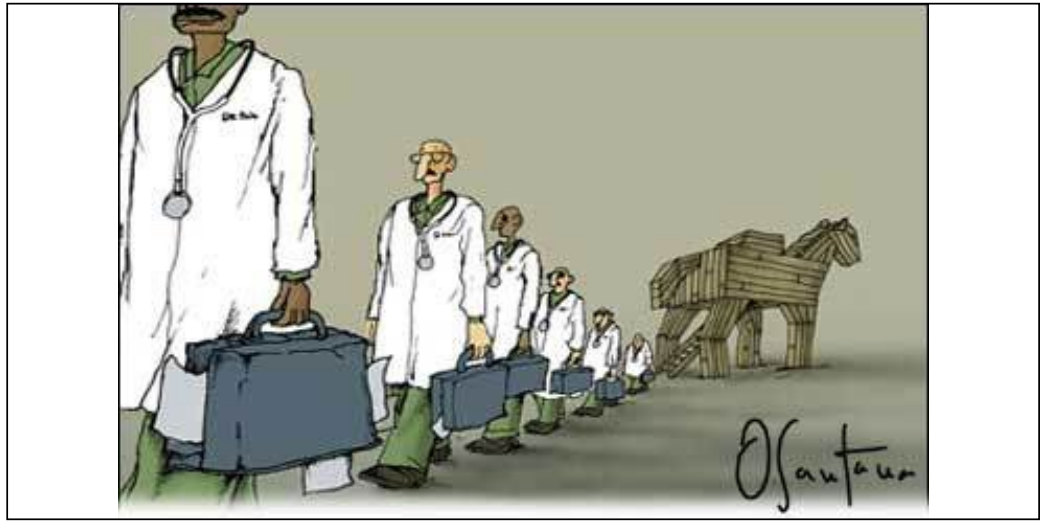

Figura 7. Charge de O Santana

FONTE: http://rafaelsasada.blogspot.com.br/2013/06/medicos-estrangeiros-no-brasil.html

A Figura 8 é uma charge que demanda conhecimentos estereotipados sobre Cuba, país que mais cederia médicos ao PMM brasileiro. A questão com os cubanos era ainda mais acirrada do que propriamente a ideia de trazer profissionais de saúde estrangeiros ao Brasil. o preconceito contra os médicos de Cuba foi tema de diversas charges, o que é abordado nas Figuras 9, 10 e 11.

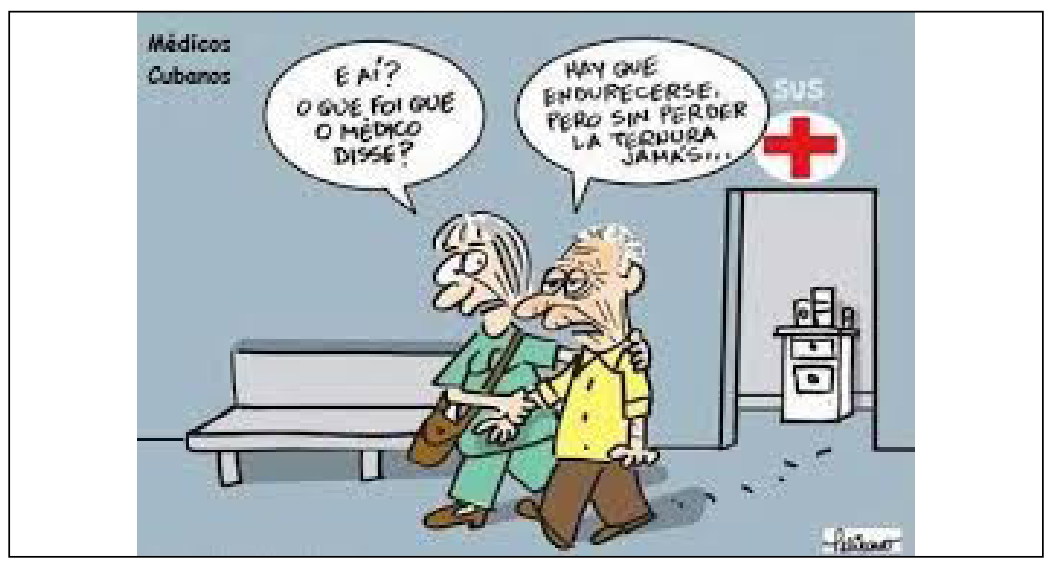

Figura 8. Charge assinada de Rir é o melhor remédio

FONTE: http://www.rireomelhoremedio.com/2013/11/medicos-eles-estao-chegando.html

A frase amplamente conhecida de Che Guevara, guerrilheiro que tem seu rosto estampado em camisetas e canecas ao redor do mundo, é repetida pelo paciente que sai da consulta com um médico cubano, na Fig. 8. A incomunicabilidade será objeto de crítica e argumento contrário ao Mais Médicos em diversas charges, como se verá logo.
Questões de multimodalidade eproduçãode sentidosem charges sobre o programaMais Médicos 
Na Figura 9, por exemplo, o ataque a todos os médicos fica patente na dificuldade de ler suas receitas - a famosa "letra de médico" -, escritas de maneira ininteligível para as pessoas que necessitam de atendimento. Ao mesmo tempo que se tece uma crítica aos médicos que escrevem receitas ilegíveis e à incomunicabilidade com o paciente, a charge opera para neutralizar o argumento de que médicos estrangeiros não poderiam se comunicar bem com pacientes brasileiros. Não faria diferença, afinal.

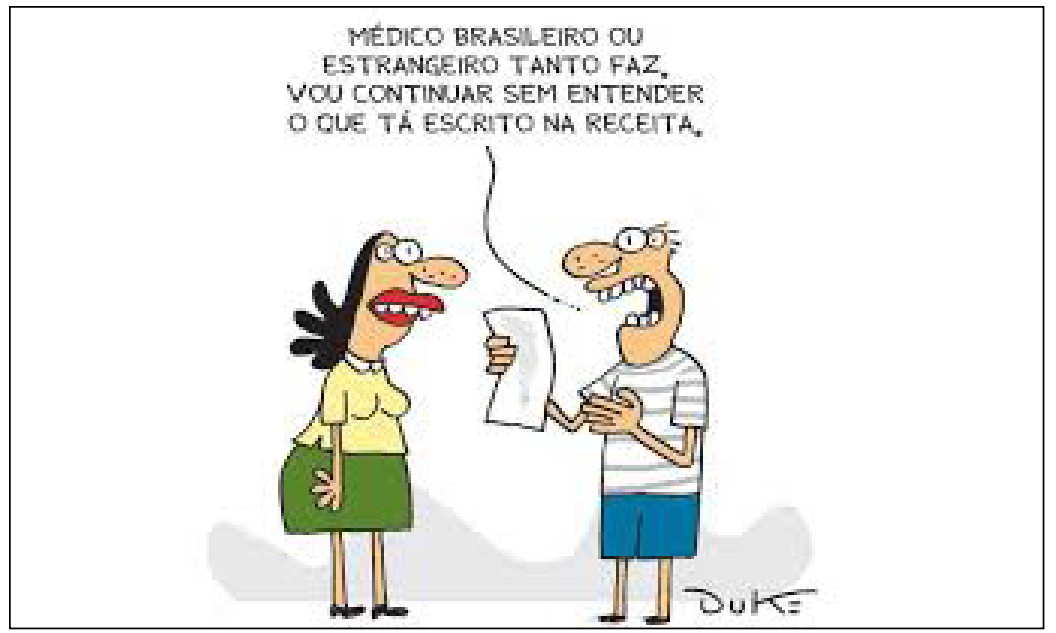

Figura 9. Charge de Duke

FONTE: http://oquetodomundoquerfalar.blogspot.com.br/2013_08_01_archive.html

O preconceito especificamente contra os médicos cubanos aparece com evidência nas Figuras 10 e 11, sendo tratado com especial contundência nesta última. A dificuldade de relacionamento e a desigualdade de condições da categoria aparece na Fig. 10, enquanto que as questões de aparência, que tocam elementos étnicos e um preconceito e cunho social, surge na Fig. 11, quando a médica cubana é comparada a uma "empregada doméstica". No Brasil, a existência de "empregadas" tem raízes culturais e históricas, e vem sendo discutida e alterada por leis e o próprio avanço social, tecnológico e econômico.

De todo modo, a construção de um posicionamento a favor do Programa Mais Médicos é inferível, nas Figuras 10 e 11, a partir da sugestão de que a crítica dos médicos brasileiros ao PMM está fundamentada no preconceito contra os cubanos, e não em algum outro elemento mais qualificado. Ao leitor, cabe compreender a mensagem de que os médicos daqui seriam preconceituosos e corporativistas. 


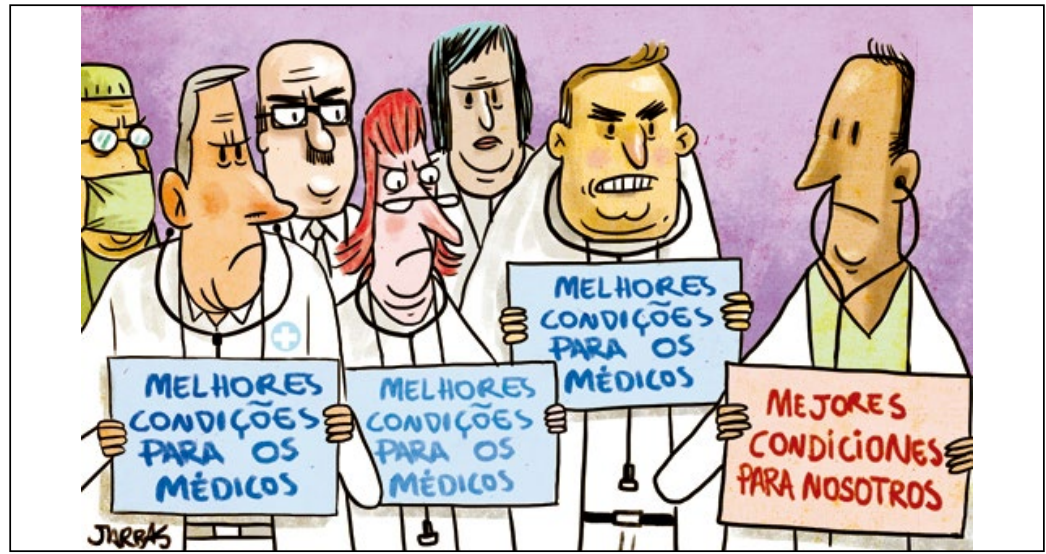

Figura 10. Charge de Jarbas

FONTE: http://www.querodesenho.com/tag/programa-mais-medicos/
Questões de multimodalidade e produção de sentidosem charges sobre o programaMais Médicos

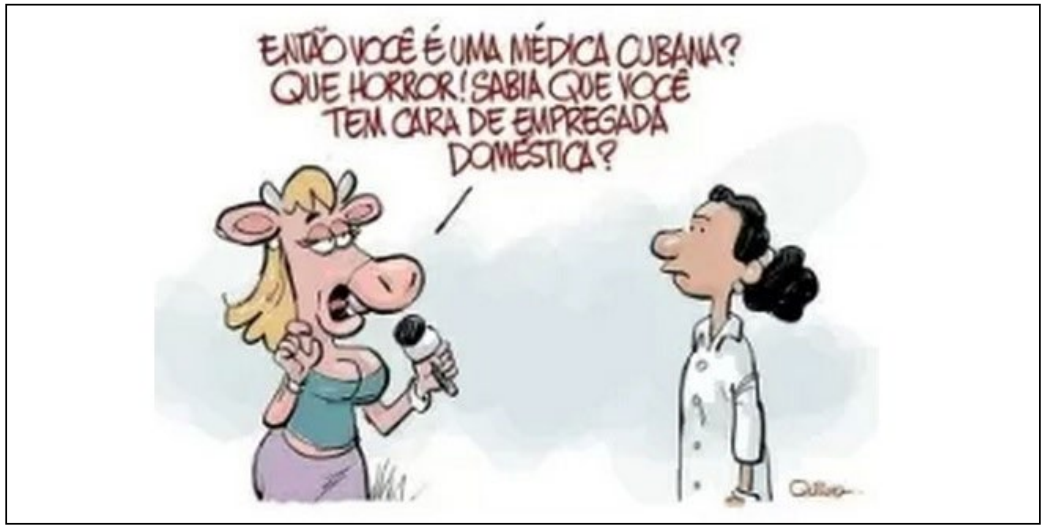

Figura 11. Charge assinada do Blog da Cidadania

FONTE: http://oquetodomundoquerfalar.blogspot.com.br/2013_08_01_archive.html

Por fim, na Fig. 12, o preconceito contra cubanos é plenamente admitido pelos "exames" que confirmam um "vírus". o trocadilho com a palavra "inCubado" precisa ser percebido para que o efeito de humor seja alcançado pelo leitor. 0 modo ligado ao layout e à mudança na fonte (versalete, versal) é, sutilmente, o responsável por mostrar ao leitor a intenção do trocadilho fundamental para a compreensão da charge e para a construção de um efeito de humor. 


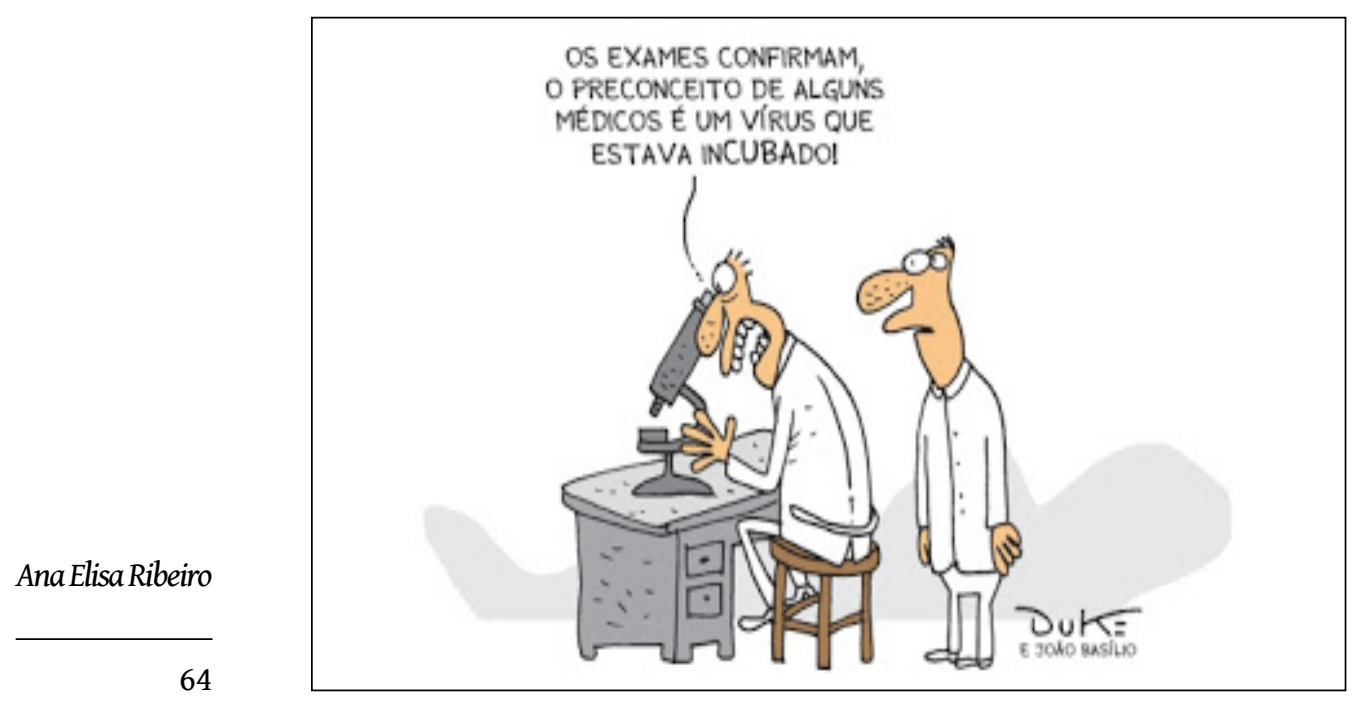

Figura. 12. Charge de Duke e João Basílio

FONTE: http://oquetodomundoquerfalar.blogspot.com.br/2013_08_01_archive.html

Um outro argumento opera para convencer o leitor de que o Programa Mais Médicos não é positivo para o Brasil: uma manobra eleitoreira da Presidente da República, buscando sua reeleição. O fato de que os índices de aprovação da então (re)candidata melhoraram depois do PMM levaram seus críticos a produzir esse tipo de texto. 0 estetoscópio - equipamento médico amplamente conhecido pela população e presente em todas as representações desse profissional - em forma de coração ${ }^{9}$ dá a ideia de que esse Programa de governo contribuirá fortemente para que Dilma seja reeleita. Presume-se, assim, que haja grande parte da população favorável ao PMM, a despeito dos críticos existentes. Uma manobra eleitoreira, no entanto, é de ser vista com desconfiança e maus olhos.

9 É de se mencionar que o gesto de fazer coração com as mãos, os dedos, é um elemento comum e muito midiático nos tempos que correm. 


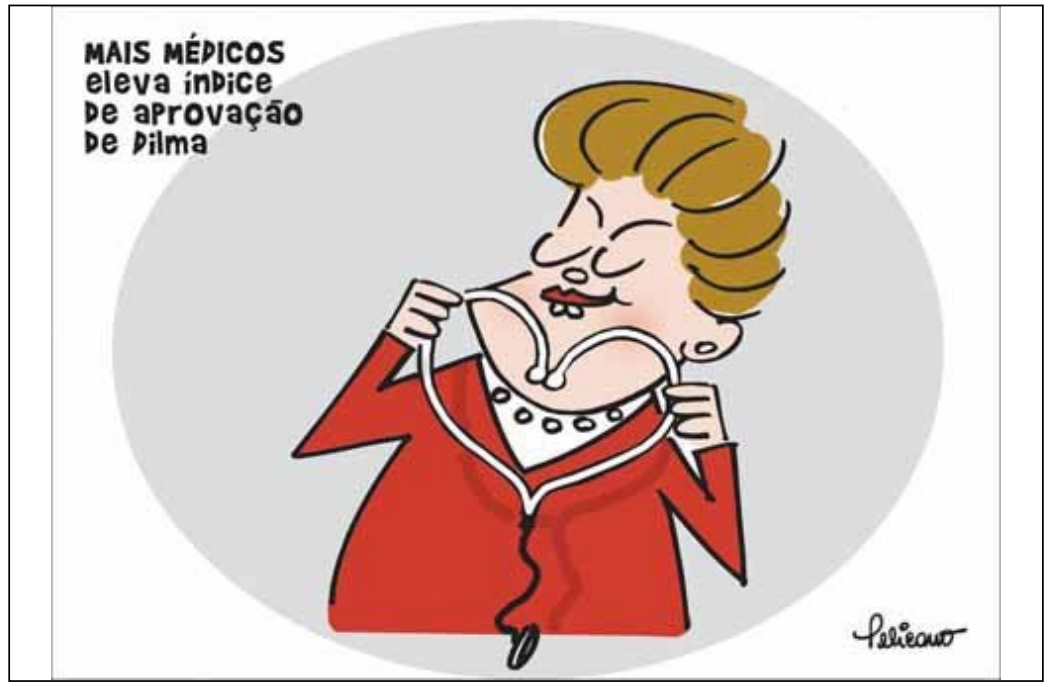

Questões de multimodalidade eprodução de sentidosem charges sobre 0 programa Mais Médicos

Figura 13. Charge de Pelicano

FONTE: http://o-xis.blogspot.com.br/p/charges_5302.html

Muito interessante para a compreensão dos textos multimodais que aqui focalizamos é a orquestração de linguagens que agora serão vistas metalinguisticamente, nas Figuras 14, 15, 16, 17 e 18. Trata-se de charges que colocaram a questão da língua estrangeira ou mesmo do sotaque como pontos nodais dos textos ou mesmo da construção de argumentos contrários ao Programa Mais Médicos. Entram em cena também tecnologias digitais, como na Fig. 14, a seguir.

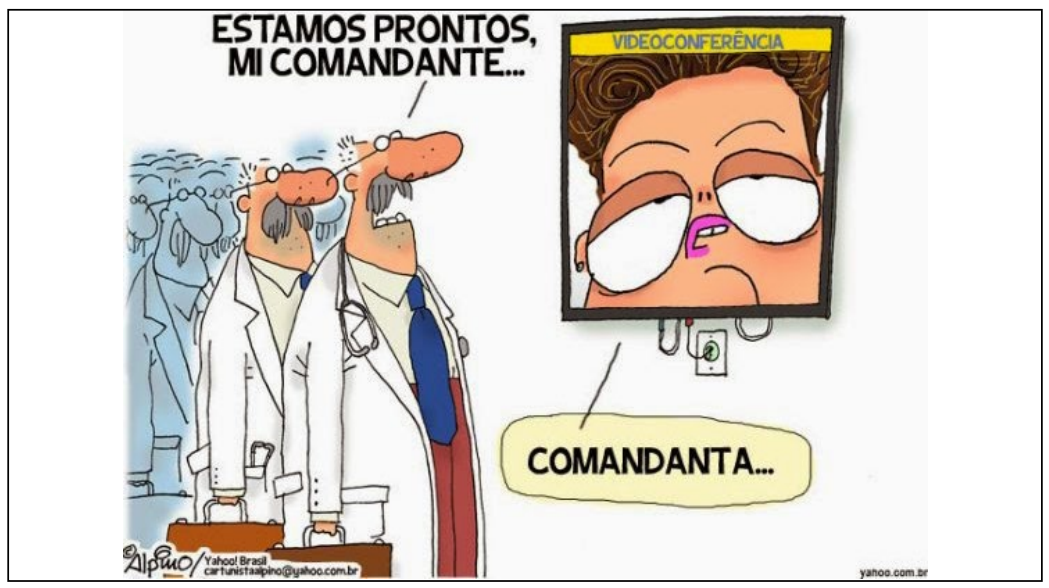

Figura 14. Charge de Alpino

FONTE: http://polibiobraga.blogspot.com.br/2014/10/cuba-teria-espioes-infiltrados-no.html 
Na Fig. 14, como se viu, mesclam-se questões variadas, todas relacionadas ao momento em que Dilma Roussef era o centro de questões ligadas ao governo. Estão na cena mostrada os médicos estrangeiros (vestidos com seus jalecos, gravatas e maletas) em videoconferência com a estadista brasileira, em plena chamada para seus postos no PMM. A resposta de Dilma, no entanto, toca uma outra questão que emergiu logo que ela assumiu seu primeiro mandato: o feminino da palavra Presidente. Dilma foi contundente ao solicitar ser chamada de Presidenta, o que também foi motivo de polêmica para a sociedade ${ }^{10}$. Mais ridicularizada por isso do que compreendida, a Presidente(a) continuou sendo atacada por esse tipo de crítica. Mais sutilmente, esta charge (Fig. 14) ridiculariza a líder brasileira, o que põe em xeque sua relação com o PMM.

As charges que dizem respeito às Figuras 15 e 16 operam palavra e imagem de maneira a mostrar consultórios em que pessoas "simples" (vide aparência da paciente na Fig. 16) são tratadas por médicos estrangeiros. No primeiro caso, o profissional entrega uma receita ou prescrição que não pode ser compreendida pela mãe do paciente pediátrico. Infere-se daí que o texto tenha sido escrito em espanhol, conforme resposta do doutor: "cómo no?". A partir disso, é possível construir um sentido negativo em relação ao Mais Médicos, sendo argumento principal o fato de que esses médicos não seriam capazes de se comunicar com a população brasileira.

No mesmo sentido, a Fig. 16 mostra um médico falante de inglês em consulta com uma senhora brasileira que não compreende o que ele diz. A pergunta do profissional é, em tradução ao português, "O que você está sentindo?", ao que a mulher responde sobre a quantidade elevada de filhos que tem. Aqui, o efeito de humor depende da mobilização de conhecimentos de inglês, de prosódia da palavra "feel", que se parece com "filho", em um português popular, sociolinguisticamente explicável. A língua portuguesa falada por camadas populares brasileiras aparece na transcrição da fala da mulher, além de haver aqui a construção multimodal de uma personagem "simples", desprivilegiada, perceptível por suas vestimentas, por seu modo de falar e pela quantidade de filhos (dez), elementos julgados comuns entre os mais pobres.

10 É interessante pensar que se tratou da primeira presidente mulher do Brasil, um país que ainda se ressente de forte violência de gênero. Não entraremos em detalhes neste trabalho, mas sugerimos a leitura de Recuero (2016). 


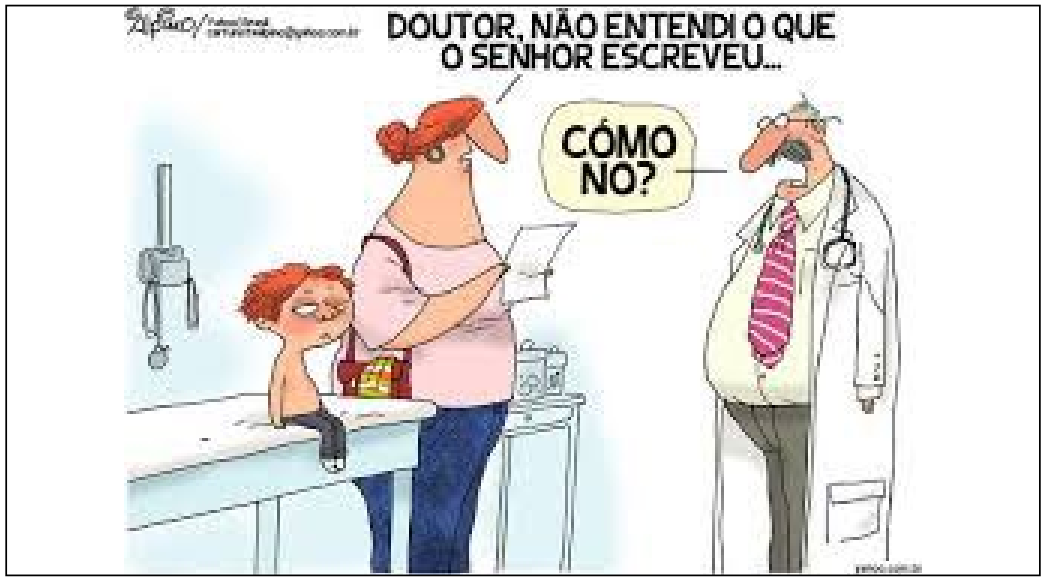

Figura 15. Charge de Alpino

FONTE: http://www.municipiosbaianos.com.br/noticia01.asp?tp=1\&nID=5383\&tema=saude

Questões de multimodalidade e produção de sentidosem charges sobre o programaMais Médicos

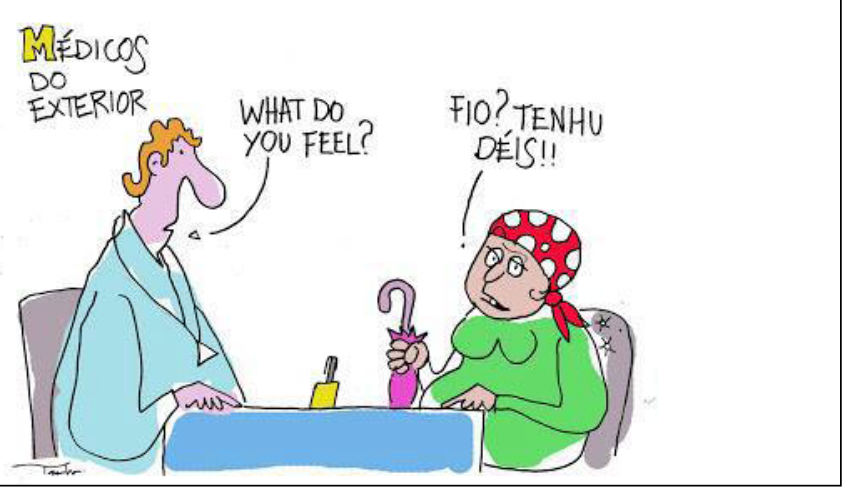

Figura 16. Charge assinada

FONTE: http://www.municipiosbaianos.com.br/noticia01.asp?tp=1\&nID=5383\&tema=saude

A charge da Fig. 17 trará uma discussão sociolinguística mais contundente em relação à incomunicabilidade que estofa o argumento contrário ao PMM. Nela, o médico estrangeiro, que depende de um dicionário para se comunicar, não pode compreender o linguajar do paciente "simples", provavelmente trabalhador do campo, conforme querem expressar seu tipo de chapéu, suas vestes e seu modo de chamar as partes do corpo. Um dicionário, como sabemos, exceto se for propositadamente de usos da língua ou popular, trará um português padrão, culto, e significará mesmo uma imensa divergência ou dificuldade se for usado como único recurso à compreensão da fala comum. A despeito disso, que é exagerado na charge, ninguém fala como nos dicionários, como qualquer linguista sabe. 


\section{Ana Elisa Ribeiro}

68

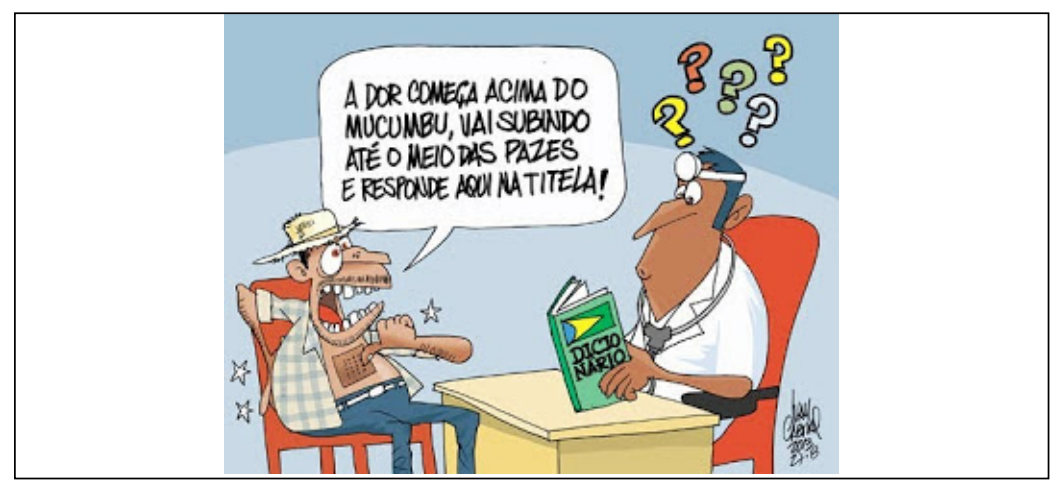

Figura 17. Charge assinada

FONTE: http://www.ofuxiqueiro.com.br/index.php/noticias/4355-mais-medicos-e-ampliado-com-beneficios-diretos-para-64-municipios-da-paraiba

Da incomunicabilidade ou da dificuldade de comunicação em um campo que deveria ser fundado na conversa, na anamnese, na interação entre as pessoas - a medicina e o atendimento médico -, até a questão dos sotaques, estas últimas charges querem construir um sentido de posicionamento contrário ao Mais Médicos, justo porque estrangeiros e a população "simples" brasileira seriam incomunicáveis. Notems a não representação de outro tipo de paciente na construção destes argumentos.

Por fim, a Fig. 18 traz uma charge que opera com imagens e palavras para construir um sentido pouco claro em relação ao PMM. O "sotaque" da sirene da ambulância na rua, diante do hospital, traz à tona a existência de médicos "importados". o paciente não parece desmerecer tais profissionais, embora seja ridícula a situação de uma sirene com sotaque, reforçada pela palavra "importado" para qualificar os médicos.

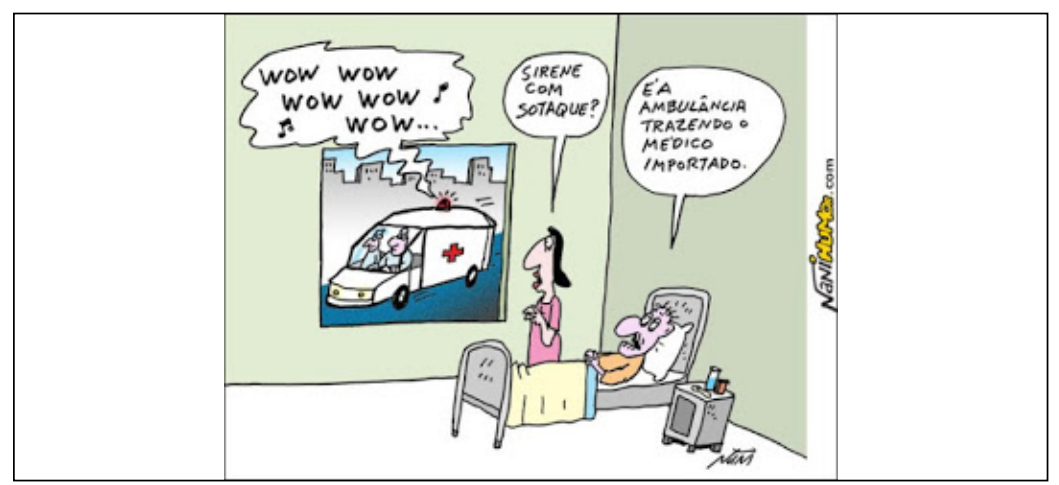

Fig. 18. Charge de Nani

FONTE: http://rafaelsasada.blogspot.com.br/2013/06/medicos-estrangeiros-no-brasil.html 
Dessa maneira, é perceptível que existam muitas maneiras de construir textos fundamentalmente multimodais (aqui, apenas palavra e imagem - com modulações de traço, cor, layout, etc.), orquestrando modos que pretendam enfatizar efeitos que o leitor pode entender como argumentos pró ou contra o Programa Mais Médicos. Esse leitor, portanto, precisa estar apto, isto é, ser capaz de mobilizar conhecimentos ligados às linguagens e às modulações escolhidas pelo produtor do texto a fim de compreender sentidos, argumentos, contra-argumentos, falácias, preconceitos expressos ou quase expressos ali, além de uma série de referências a outros textos, que podem ser compostos de palavras, imagens, sons, etc.

\section{Considerações finais}

Questões de multimodalidade eproduçãode sentidosem charges sobre 0 programaMais Médicos

Se aqui nos ocupamos de tratar, brevemente, apenas das charges, é importante estender esta análise às charges em seus espaços originais de publicação. Em vários casos, estes quadros foram publicados como textos principais, mas, em outros, foram complementares ou ilustrativos, ou reafirmadores de textos compostos com palavras. Em muitos outros casos, como vem ocorrendo cada vez mais na internet, as charges foram publicadas primeiro em jornais ou revistas e, em seguida, foram "transplantadas" para outros espaços de publicação e textos. Os textos que eventualmente as acompanharam, em sua origem, podem agora ser outros, ressignificados por blogueiros ou pelas pessoas que os compartilham - e comentam - nas redes sociais. Os sentidos daí construídos podem se alterar muito em relação à proposta inicial.

Desse modo, com tantas relações que podem compor e explicar um texto multimodal, desde a sua natureza modal (palavra, imagem, som...) até seus modos de circulação (que nos fazem pensar em affordances específicas), é importante assumir que "[A] a linguística mainstream tem focalizado amplamente a forma - em termos semióticos, o significado; o sentido tem sido exportado para disciplinas periféricas - a semântica, a pragmática, a sociolinguística, a estilística" (KRESS, 2003, p. 41), mas que é necessário compreender o texto na convergência de mídias, com as mudanças teóricas e epistemológicas que isso possa demandar.

Segundo Kress (2003), se antes as pessoas (leitores, escritores...) apenas usavam os recursos, sem os poderem mudar, agora o uso dos recursos representacionais é agentivo e transformativo. Para o autor, são “[P]profundas mudanças sociais, econômicas e tecnológicas que, afinal, 
redesenharão o futuro do letramento" (p. 176), como tem ocorrido. 0 aumento e a diversidade das formas multimodais dos textos contemporâneos ${ }^{11}$, o que inclui modos de produção e de circulação, além das intervenções possíveis nos textos (atualmente mais vulneráveis a outras coautorias), torna "essencial que repensemos nossas noções do que seja a leitura" (KRESS, 2003, p. 141). Daí decorre, é claro, que pensemos e contribuamos para o letramento de maneira múltipla e atenta às relações modais hoje possíveis.

\section{REFERÊNCIAS}

CAZDEN, Courtney et al. A pedagogy of multiliteracies: Designing social futures. Harvard Educational Review, n. 66, 1, Spring, 1996.

CHARTIER, Roger. Os desafios da escrita. Trad. Fulvia M. L. Moretto. São Paulo: UNESP, 2002.

CHARTIER, Roger. Cultura escrita, literatura e história: Conversas de Roger Chartier com Carlos Aguirre Anaya, Jesús Anaya Rosique, Daniel Goldin e Antônio Saborit. Porto Alegre: Artmed, 2001.

CHARTIER, Roger. A ordem dos livros: leitores, autores e bibliotecas na Europa entre os séculos XIV e XVIII. 2. ed. Trad. Mary Del Priore. Brasília: Editora Universidade de Brasília, 1998.

CHARTIER, Roger. A aventura do livro: do leitor ao navegador. Trad. Reginaldo de Moraes. São Paulo: UNESP, 1998a. (Prismas)

KRESS, Gunther. Literacy in the new media age. London: Routledge, 2003.

KRESS; Gunther; VAN LEEUWEN, Theo. Reading images: The grammar of visual design. 2 ed. London: Routledge, 2006.

11 Importante frisar que a charge é um gênero antigo, publicado em jornais e revistas tradicionais. No entanto, seus modos de produção, a rapidez com que são compartilhadas, isto é, seus modos de circulação e ressignificação estão alterados nos dias de hoje. 
PROGRAMA MAIS MÉDICOS (PMM), Governo Federal. Disponível em: <http://maismedicos.gov.br/>. Acesso em: 27 fev. 2015.

RECUERO, Raquel. o twitter como esfera pública: como foram descritos os candidatos durante os debates presidenciais do $2^{\circ}$ turno de 2014? Revista Brasileira de Linguística Aplicada, Belo Horizonte, v. 16, n. 1, p. 157-180, 2016.

Questões de multimodalidade eprodução de sentidosem

RECUERO, Raquel. A conversação em rede: A comunicação mediacharges sobre o da pelo computador e as redes sociais na internet. Porto Alegre: Sulina, 2012. programaMais Médicos

RECUERO, Raquel. Redes sociais na internet. Porto Alegre: Sulina, 71 2009.

ROJO, Roxane. Pedagogia dos multiletramentos: diversidade cultural e de linguagem na escola. In: ROJO, Roxane; MOURA, Eduardo. (Orgs.) Multiletramentos na escola. São Paulo: Parábola Editorial, 2012. 
